\title{
OTR3 Notificações de eventos adversos e queixas técnicas: interface entre Divisão de Atendimento ao Cliente e Assessoria Clínica de Bio-Manguinhos
}

Linda Khalili Boukai ${ }^{1}$, Adriana dos Santos Duarte ${ }^{1}$, Monique Amorim Pimenta ${ }^{1}$, Alessandra Bógio ${ }^{1}$, Cíntia Nunes Cardoso Lopes ${ }^{1}$, Paulo Roberto Gomes dos Santos ${ }^{1}$, Ramon Lemos Calaça ${ }^{1}$, Ricardo Cristiano Brum $^{1}$, Patrícia Mouta Nunes de Oliveira ${ }^{1}$

${ }^{1}$ Bio-Manguinhos, Fiocruz, Rio de Janeiro, RJ

Introdução: A Divisão de Atendimento ao Cliente e Pós Marketing (DIACM) centraliza o recebimento das notificações referentes aos produtos do portfólio de Bio-Manguinhos e tem a responsabilidade de retornar uma resposta dentro dos prazos estabelecidos em POP (Procedimento Operacional Padronizado). Muitas vezes, a tratativa das notificações é compartilhada com outras Unidades Organizacionais (UO), como no presente trabalho que enfatiza a cooperação e a integração com a Assessoria Clínica (ASCLIN).

Objetivo: Reportar a frequência relativa de eventos adversos relacionados aos biofármacos e vacinas, e queixas técnicas relacionadas a kits diagnósticos em usuários brasileiros.

Metodologia: Durante o primeiro atendimento, a DIACM coleta informações chave relacionadas às notificações. Todas as informações são registradas em sistema operacional, classificadas de acordo com critérios pré-definidos e, quando pertinente, encaminhadas às UO responsáveis para tratativa do caso. A DIACM tem uma relação estreita com os setores de interface, baseada em fluxogramas de comunicação pré-estabelecidos que padronizam as ações. Os casos de notificações de eventos adversos e queixas técnicas são compartilhados com a Assessoria Clínica: Farmacovigilância e Tecnovigilância. Estes setores são responsáveis pela investigação da causalidade e notificação do caso ao órgão regulatório por meio do sistema NOTIVISA, conforme preconizado pela RDC n 04/2009 e RDC nํ 67/2009. Eventos adversos são tratados com prioridade pelos profissionais da ASCLIN que interagem com a DIACM e são responsáveis pelo retorno de uma resposta ao notificador. Um parecer técnico no qual consta a conclusão com as devidas ações corretivas e/ou planejamento das ações preventivas é emitido após o término das investigações.

Resultados: No ano de 2013, foram entregues ao Ministério da Saúde 4.709.836 reativos (reações) para diagnóstico (exceto o produto NAT), 92.513.825 vacinas (doses) e 11.061 .459 biofármacos (frascos). Destes, foram registradas um total de 66 notificações para linha de vacinas, 07 para os biofármacos e 42 para os reativos (exceto o produto NAT). Para a linha das vacinas os dados revelam que apenas $0,00002 \%$ referem-se a eventos adversos. Para os Biofármacos, 
0,00001\%. Os dados analisados pela Farmacovigilância, revelam que nenhuma notificação teve sua causa estritamente associada ao produto, mas sim a diversas doenças de base devidamente investigadas. Para Tecnovigilância, nenhuma notificação teve sua causa associada à falhas de fabricação do produto. Neste caso, medidas alternativas, como por exemplo, esclarecimento de dúvidas e intervenção técnica nos equipamentos foram eficientes e suficientes para a correção dos problemas relatados nas notificações.

Conclusão: Os resultados apresentados indicam que os reativos para diagnóstico produzidos por Bio-Manguinhos estão dentro dos melhores padrões de qualidade quando se trata de diagnóstico de uso "in vitro".

Palavras-Chave: Atendimento, Farmacovigilância, Tecnovigilância 